\title{
Investigation of aromatic hydrocarbon inclusion into cyclodextrins by Raman spectroscopy and thermal analysis
}

\author{
Tijunelyte Inga ${ }^{1}$, Dupont Nathalie ${ }^{1}$, Milosevic Irena ${ }^{1}$, Barbey Carole ${ }^{1}$, Rinnert Emmanuel ${ }^{2}$, \\ Lidgi-Guigui Nathalie ${ }^{1}$, Guenin Erwann ${ }^{1}$, de la Chapelle Marc Lamy ${ }^{1, *}$
}

${ }^{1}$ Univ Paris 13, Lab CSPBAT UMR CNRS 7244, UFR Sante Med Biol Humaine, 74 Rue Marcel Cachin, F-93017 Bobigny, France.

${ }^{2}$ IFREMER, Lab Detect Capteurs \& Mesures, Unite Rech \& Dev Technol, CS10070, F-29280 Plouzane, France.

* Corresponding author : Marc Lamy de la Chapelle, email address : marc.lamydelachapelle@univparis13.fr

\begin{abstract}
:
Among various cavitand molecules, cyclodextrins are extensively studied due to their ability to form host-guest complexes with small hydrophobic molecules. Aiming to explore cyclodextrin implementation on the scopes related to the environmental pollution monitoring or remediation, extensive studies for understanding the cyclodextrin-based host-guest complex formation with selected targeted substances are conducted. In this context, two polycyclic aromatic hydrocarbons, naphthalene and fluoranthene as well as toluene as a member of volatile organic compounds, were studied regarding their ability to encapsulate into cyclodextrin cavities. Synthesised complexes were examined by thermogravimetric analysis combined with Raman spectroscopy. The obtained results demonstrated that the size between targeted molecules and the cyclodextrin cavities strongly correlates with its ability to engage in complexation. Thus, this latter parameter plays an important role in the inclusion complex formation as well as in the strength of the interaction between the molecules.
\end{abstract}

Keywords: Raman spectroscopy, Thermogravimetric analysis, Cyclodextrin, Polyaromatic hydrocarbons, PAH, Host-guest complex 


\section{Introduction}

Environmental water pollution by organic compounds is a worldwide concern due to its continuous emission in both natural (Kvenvolden and Cooper 2003) and anthropogenic (Readman et al. 1992) ways. The contaminants, consisting of two or more fused aromatic rings known as polycyclic aromatic hydrocarbons (PAHs) are a group of pollutants which have received considerable attention because of their documented significant toxicity and carcinogenicity (Diggs et al. 2011; Harris et al. 2013; Lienig 1980; Varanasi et al. 1987). Therefore, constant monitoring of these water contaminants at the trace level is of first importance regarding the latest European Water Framework Directives (2000/60/EC, 2006/118/EC and 2006/11/EC).

Within this scope many efforts have been devoted for the development of an analytical tool capable of sensitive and rapid detection of chemical water bodies with minimal sample handling (Pejcic et al. 2007). In the course of last decades, Surface Enhanced Raman Spectroscopy (SERS) based pollutant detection has attracted more and more interest (Bantz and Haynes 2009; Carron et al. 1992; Costa et al. 2006; Guerrini et al. 2009; Halvorson and Vikesland 2010). SERS is based on the exploitation of the optical properties of metallic nanostructures and especially on their ability to provide a tremendous enhancement of the 
electromagnetic field at the nanostructure vicinity. Any molecules close to the nanostructure surface can benefit from this enhancement and scatter a Raman signal magnified by a factor up to $10^{10}$. This highly sensitive method allows observing chemical compounds at the trace level as low as the single molecule sensitivity (Chang et al. 2013; Yang et al. 2010) and can provide quantitative and qualitative multi-analysis in complex environment (Pfannkuche et al. 2012). However, in SERS configuration, the molecules that are close to the nanostructure surface will experience the high field enhancement and the Raman spectrum will be then composed of all the spectroscopic features of these molecules including the non-targeted ones. To have a specific detection, it is then necessary to pre-concentrate the targeted molecules at the nanostructure surface. For this, a specific molecular layer that exhibits higher affinity to the targeted molecules has to be used. Among different strategies to design a SERS-based nanosensor able to pre-concentrate aromatic compounds, supramolecular cage systems as cyclodextrins or calixarenes appear to be particularly promising (Guerrini et al. 2006; Hill et al. 1999; Shi et al. 2012; Xie et al. 2011; Xie et al. 2010).

Cyclodextrins (CDs) are natural cyclic oligosaccharides. The three commercially available CDs: $\alpha-C D, \beta-C D$ and $\gamma-C D$ are consisting of six, seven or eight $\alpha$-D-glucose units, respectively, linked though $\alpha-1,4$ glycosidic bonds (figure 1a)). Torus-shaped structure of CDs possesses a relatively hydrophobic internal cavity which is known to provide binding sites for wide variety of molecules (Del Valle 2004). Mainly for this reason CDs are applied in food (Astray et al. 2009), pharmaceuticals (Loftsson and Brewster 1996), cosmetics (Buschmann and Schollmeyer 2002), bioconversion (Dufosse et al. 1999), textile industries (Cireli and Yurdakul 2006) as well as in environmental research (Viglianti et al. 2006).

Fig.1 Illustrated scheme of (a) molecular and 3D structures of three forms of CDs, with indications of diameters of the cavities, (b) molecular structure of the three selected pollutants with their sizes.

Host-guest complex formation between CDs and organic molecules have been widely studied by different techniques, such as thermo-analytical methods, microscopy, chromatography and spectroscopy (Singh et al. 2010). For solid state analysis, Raman (Amado et al. 1994; Amado and Ribeiro-Claro 2000) and Infra-Red (García-Zubiri et al. 2004; Nagao et al. 2009) spectroscopies are the most used techniques to collect important evidences on the complex formation, thanks to changes in the molecular vibrational modes (frequency and relative intensity) due to the molecular interaction between the host and the guest molecules. 
However, literature reveals that complexes formed between CDs and non-polar aromatic compounds are still undergoing difficulties in spectroscopic based analysis (García-Zubiri et al. 2004) due to very weak molecular interactions. In the present work, three forms of CDs were employed in host-guest complexes formation with toluene (TOL), naphthalene (NAP) and fluoranthene (FL). Complexes in solid state were synthesised and studied by Raman spectroscopy and thermogravimetric (TG) analysis. We investigated the molecular affinity comparing the size of the guest with the diameter of the host cavity. We also studied the changing in vibrational modes of the complexes in order to subsequently use enhanced spectroscopy techniques for the detection of those compounds in the wild aquatic environments.

\section{Experimental}

\section{Materials}

Pharmaceutical grade CDs $(\alpha, \beta$ and $\gamma \mathrm{CD})$ were purchased from Wacker Chemie (Germany) and used without further purification. Aromatic compounds: TOL, NAP and FL, and ethanol were obtained from Sigma-Aldrich (France) at high purity grade and were used as received.

\section{Inclusion complex preparation}

Following the procedure described in literature (Sardo et al. 2009), based on co-precipitation method, saturated aqueous solutions of $\alpha \mathrm{CD}, \beta \mathrm{CD}$ and $\gamma \mathrm{CD}$ were mixed with aromatic compounds (TOL, NAP and FL) dissolved in ethanol at the concentration of $50 \mathrm{mM}$. The addition of the pollutant solutions into CDs, were made drop-wise using strong agitation at ambient temperature. This process led to immediate formation of white precipitants. Mixed solutions were then kept in shaker for 2 hours and precipitants were collected using centrifuge. To make sure that there were no non-included aromatic compounds precipitants were briefly washed with ethanol/water solution 50/50 (v/v), and dried for 2 days at room temperature.

To obtain additional information on complex formation extensive study was performed on $\beta C D$ :NAP complexes. For this NAP dissolved in ethanol was mixed with saturated $\beta C D$ solution at different molar ratios ( $2 \beta C D$ : 1 NAP, $1 \beta C D: 1 N A P$ and $1 \beta C D: 2 N A P)$. Further steps of sample collection, washing and drying were performed as previously described. 
For analysis of CDs based selectivity towards the pollutant molecules the complexes were prepared as follows: TOL, NAP and FL were dissolved together in ethanol at $50 \mathrm{mM}$ concentration and added in saturated aqueous solutions of each: $\beta \mathrm{CD}$ and $\gamma \mathrm{CD}$. Ethanol solution containing both TOL and NAP at $50 \mathrm{mM}$ concentration was added into $\alpha \mathrm{CD}$ solution. Further steps of sample collection, washing and drying were performed as previously described.

\section{Thermogravimetric analysis}

For TG analysis LabSys evo instrument (SETARAM) was used. Each sample (8-12 mg) was kept for 1 hour at $30{ }^{\circ} \mathrm{C}$ in alumina pan before heating over the temperature range from 30 to $600{ }^{\circ} \mathrm{C}$ under argon atmosphere with the flow rate of $20 \mathrm{~mL} / \mathrm{min}$. The empty sealed alumina pan was used as reference. For data processing Calisto software was used.

\section{Raman spectroscopy measurements}

Raman spectra of $\alpha, \beta$ and $\gamma \mathrm{CD}$, TOL, NAP and FL as well as of their inclusion complexes in solid powder were recorded using Xplora ONE (Horiba scientific) microspectrometer. Laser excitation wavelength of $785 \mathrm{~nm}$ with a power of $8 \mathrm{~mW}$ was focused on the sample with x100 objective (N.A. 0.9). Integration time for signal collection was set to $60 \mathrm{~s}$ for CDs and their complexes and to $5 \mathrm{~s}$ for aromatic compounds. Each spectrum is the average of two repetitive measurements. Applied grating of 1200 grooves $/ \mathrm{mm}$ has ensured spectral resolution of less than $1 \mathrm{~cm}^{-1}$. It is important to note, that the studied aromatic molecules adsorb in the UV range (Koban et al. 2004; Maeda et al. 2012; Saranya et al. 2011). Thus, the energy of the near infrared laser could not match with any electronic transitions of these compounds and as a consequence the measured Raman scattering is not in resonant condition.

\section{Computational}

All calculations were carried out using the Gaussian09 suite of programs (Frisch et al. 2009). Following full geometry optimization of FL with $\mathrm{C} 2 \mathrm{v}$ symmetry using the density functional three-parameters hybrid model B3LYP (Becke 1996; Lee et al. 1988) with the 6-311G (d,p) basis set, vibrational frequencies and Raman activities were calculated. The B3LYP method with the $6-311 \mathrm{G}(\mathrm{d}, \mathrm{p})$ basis set is frequently used in predicting vibrational spectra of poly 
aromatic molecules. Raman intensities were computed from activities with GaussSum 3.0 (O'Boyle et al. 2008) using an excitation wavelength of $785 \mathrm{~nm}$. The calculated harmonic frequencies of $\mathrm{CH}$ stretching vibrations were scaled by a factor of 0.96 and all the other frequencies by 0.98 to allow a good agreement with observed ones for FL alone within almost $10 \mathrm{~cm}^{-1}$ on the whole spectra. Gaussview 5 (Dennington et al. 2009) was used to visualize the participation and direction of atoms in vibrational normal modes in order to make bands assignments easier.

\section{Results and discussion}

\section{Study of complexes formed between $\beta-C D$ and variable concentration of NAP}

Aiming to determine the relevant parameters that describe the host-guest interaction, we first studied the ratio between the host and the guest in the complex $\beta C D$ :NAP. For this purpose different molar ratios (2 $\beta C D$ : 1 NAP, $1 \beta C D$ : 1 NAP and 1 $\beta C D: 2 N A P)$ between the host and the guest were used to form the complexes. Two techniques: TG analysis and Raman spectroscopy were then employed to analyze the complexes in solid state.

\subsection{Thermogravimetric analysis}

Thermal analysis is a powerful tool to study the complex formation between guest molecules and $\mathrm{CD}$ and to evaluate the inclusion compound stoichiometry (Giordano et al. 2001). Among the various thermo-analytical techniques, TG analysis is frequently used to determine whether

the guest exhibits some changes in its phase transition temperatures indicating inclusion complex formation.

The thermograms and the derivatives of the three prepared stoichiometries regarding molar ratio ( $2 \beta C D$ :1NAP, $1 \beta C D: 1 \mathrm{NAP}$ and $1 \beta \mathrm{CD}: 2 \mathrm{NAP}$ ), as well as the thermograms of pure compounds are presented in figure 2 .

Isolated CD thermal degradation profile consists of three parts. In the first stage, a gradual loss of hydrated water from ambient to $120^{\circ} \mathrm{C}$ corresponding to the dehydration process can be recorded. During the second stage, in a temperature range between 270 and $350{ }^{\circ} \mathrm{C}$ single step weight loss is observed, corresponding to the thermal breaking of $\mathrm{CD}$ ring and further glucosidic ring decomposition (Russell and McNamara 1989). Remaining 30-40\% of residue is then showing loss in mass at a temperature range upon $350{ }^{\circ} \mathrm{C}$ and is assigned to a slow degradation of char (Trotta et al. 2000). On the other hand, pure aromatic compounds 
decompose at much lower temperature. In the case of NAP, the thermal decomposition occurs in one step between 80 and $160^{\circ} \mathrm{C}$ temperature range.

The TG curves of the complexes are quite different from those of pure components. Worth to remind, that complexes were prepared in aqueous solution and should be considered as ternary water-guest-CD systems. In themograms, the initial weight loss observed until $120^{\circ} \mathrm{C}$ is attributed to the release of water molecules. However, it is noticeable that the number of water molecules is continuously decreasing within the complexes with growing number of the guest (table 1). This change in number of water can be contemplated as a first proof of the complex formation since the inclusion process is considered as the replacement of the internal water molecules by a guest. Additionally, a peak around $62{ }^{\circ} \mathrm{C}$ can be observed on the derivatives of TG analysis curves for some complexes. This peak might be assigned to the ethanol molecules remaining after complexes formation. However, since the evaporating temperature is close to boiling point of the ethanol, we assume that the ethanol does not form complexes with the $\mathrm{CD}$ molecule. Further analysis of the thermograms revealed no peak corresponding to free NAP molecules decomposition after the complex formation. Instead, a small endothermic peak centred at around $268^{\circ} \mathrm{C}$ appears for $2 \beta C D: 1 N A P$ and $1 \beta C D: 1 N A P$ complex systems. Considering comparable mass loss in the complexes (table 1) the peak around $268{ }^{\circ} \mathrm{C}$ could be assigned to a thermal decomposition of NAP placed inside the CD cavity. Indeed, since this temperature is intermediate between the ones observed for individual CD and for individual NAP, we assume that it should be assigned to third process corresponding to the decomposition of NAP included inside the CD. Similar shift in guest decomposition temperature have been already observed by other groups (Nolasco et al. 2009; Sardo et al. 2009). The shift in decomposition temperature between free NAP and the one embedded into host indicates that the host-guest interaction protects the pollutant molecules from early volatilization. For the system with higher concentration of NAP (1 $\beta C D: 2 N A P)$, the latter peak is found slightly shifted to $270{ }^{\circ} \mathrm{C}$. Moreover, a new peak at lower temperature, centred at around $186^{\circ} \mathrm{C}$ can be observed and assigned to the NAP molecules placed outside the cavities. However, the higher decomposition temperature of those NAP molecules in comparison with free NAP signifies that they are in interaction with the complex.

Finally, the weight loss in temperature range from $270{ }^{\circ} \mathrm{C}$ to $350{ }^{\circ} \mathrm{C}$ was observed and assigned to the $\mathrm{CD}$ decomposition. A slight shift of $10^{\circ} \mathrm{C}$ to lower degradation temperature can be noticed when comparing with the free CD decomposition. This slight shift could be 
induced by the engaged guest which disorders the hydrogen bonded supramolecular structure of CD (Trotta et al. 2000).

The quantification of the mass losses upon temperature increase provides the information on the molar ratio between $\mathrm{CD}, \mathrm{NAP}$ and $\mathrm{H}_{2} \mathrm{O}$ in the systems. Calculated stoichiometries of the complexes are summarized in table 1.

Fig.2 Top: thermograms of the reference molecules: NAP and $\beta C D$ presented as dot and dash lines respectively, and of the inclusion complexes formed mixing different molar ratios: 2 $\beta C D$ :1NAP (red curve), 1 $\beta C D: 1 N A P$ (blue curve), $1 \beta C D: 2 N A P$ (violet curve). Bottom: derivatives of the TG curves.

As explained previously, the studied complexes are actually ternary $\beta \mathrm{CD}-\mathrm{NAP}-\mathrm{H}_{2} \mathrm{O}$ systems. Nevertheless, an increase of the initial guest concentration leads to an increase of the NAP molecules included into CD cavities. On the contrary, the number of water molecules per CD decreases in agreement with the increasing number of engaged NAP molecules, as already mentioned proving the successful replacement of the water molecules.

Table 1 TG analysis based calculation on stoichiometry for inclusion complexes

\begin{tabular}{cccccc}
\hline System & $\begin{array}{c}\text { Theoretical } \\
\text { stoichiometry }\end{array}$ & $\begin{array}{c}\%(w t) \\
(\text { Guest })\end{array}$ & $\begin{array}{c}\%(w t) \\
\left(\mathrm{H}_{2} \mathrm{O}\right)\end{array}$ & $\begin{array}{c}\text { Calculated } \\
\text { stoichiometry }\end{array}$ & $\begin{array}{c}\text { Water per } \\
C D\end{array}$ \\
\hline $2 \beta \mathrm{CD}: 1 \mathrm{NAP}$ & $2: 1$ & 9.2 & 4.1 & $2: 1$ & 10 \\
$1 \beta \mathrm{CD}: 1 \mathrm{NAP}$ & $1: 1$ & 5.1 & 7.2 & $1: 1$ & 7 \\
1 $\beta \mathrm{CD}: 2 \mathrm{NAP}$ & $1: 2$ & 10.6 & 4.6 & $2: 3$ & 5 \\
\hline
\end{tabular}

The cavity of $\beta C D$ is generally considered large enough to accommodate aromatic guest molecule (Köhler and Grczelschak-Mick 2013). The 1ßCD:1NAP stoichiometry was observed to be in good agreement with the predicted one, as well as in case of $2 \beta \mathrm{CD}: 1 \mathrm{NAP}$ formed inclusion complex where 1 molecule of NAP is between $2 \beta \mathrm{CD}$ molecules. Unusual host-to-guest stoichiometry was calculated for the last complex with the highest NAP concentration. Calculated stoichiometry of 3 NAP molecules per $2 \beta C D$ was found. Similar stoichiometry has been already observed and documented for a complex formed between $\beta C D$ and 1,10-phenanthroline (Liu et al. 2004). With the help of X-ray diffraction authors 
have observed that two 1,10-phenanthroline molecules were individually included into two $\beta C D$ cavities and stabilized by the third guest molecule located in the interstitial space between two head-to-head CD molecules. The observed stoichiometry of $2 \beta \mathrm{CD}$ :3NAP should have similar structure. In the complex two NAP molecules which were found to decompose at $270{ }^{\circ} \mathrm{C}$ are included into $2 \beta \mathrm{CD}$ individually. These $1 \beta \mathrm{CD}$ :1NAP complexes are then stabilized by a third NAP molecule placed outside the CD. NAP molecules located in the interstitial space between two complexes decompose at around $186{ }^{\circ} \mathrm{C}$ as observed in TG analysis.

\subsection{Raman spectroscopy based analysis}

The complexes synthesised mixing different molar ratios between $\beta C D$ and NAP were then studied by Raman spectroscopy. Figure 3 presents the Raman spectra of the native $\beta C D$, of the NAP and of the three inclusion complexes: $2 \beta C D$ :1NAP, $1 \beta C D: 1 N A P, 1 \beta C D: 2 N A P$.

Fig.3 Raman spectra of the $\beta C D$ (a), of the NAP (b) and of the inclusion complexes (c), (d), (e) obtained after mixing $\beta C D$ with NAP in molar equivalents of 2:1, 1:1 and 1:2 respectively.

Peaks corresponding to naphthalene were observed in the spectra of all the complexes. Moreover, the proof of molecular inclusion and interaction with the CD cavities was clearly noticeable by comparing the relative intensities of isolated NAP peaks with the ones of NAP included in the complexes. Significant differences in intensities can be observed for several peaks (figure 4).

Fig.4 Three vibrational modes of NAP which are the most impacted by the interaction with $\beta C D$.

First, the one located at $761 \mathrm{~cm}^{-1}$, corresponding to ring breathing mode and C-C central stretch, appears as the most intensive peak in the NAP spectrum whereas it is remarkably diminished in the spectra of complexes. On the contrary, the peak at $1379 \mathrm{~cm}^{-1}$ : assigned to a $\mathrm{C}-\mathrm{C}$ stretching and ring deformation is becoming the most intense mode when the NAP is embedded into the cavity of the CD. Other modes which are varying after the complex formation are less obvious in the presented graph thus their relative intensities and positions 
are summarized in table 2. The peak located at $1379 \mathrm{~cm}^{-1}$ was used as reference for the relative intensities calculation given in the table 2. An increase of the relative intensity is clearly observed for the C-C-C bending at $508 \mathrm{~cm}^{-1}$. On the contrary, the $\mathrm{C}-\mathrm{H}$ out of plane stretching mode at $3050 \mathrm{~cm}^{-1}$ as well as in plane $\mathrm{C}=\mathrm{C}$ stretching at $1575 \mathrm{~cm}^{-1}$ are less visible when NAP is included into CD. The observed change indicates that the stretching modes inducing a potential interaction of $\mathrm{H}$ atoms with the $\mathrm{CD}$ as well as the radial mode or the $\mathrm{C}-\mathrm{H}$ stretching exhibit a lower intensity compared to the other modes; that is an evidence of the inclusion of the NAP in the $\beta C D$ cavity.

Table 2 Positions of the vibrational modes and their calculated relative intensities for free NAP and NAP included in the $\beta C D$. Assignment of isolated NAP vibrational modes found in literature (Srivastava and Singh 2007)

\begin{tabular}{ccccccccc}
\hline \multicolumn{2}{c}{ 2CD:1NAP } & 1CD:1NAP & 1CD:2NAP & Assignment \\
\hline Peak & Rel.Int & Peak & Rel.Int & Peak & Rel.Int & Peak & Rel.Int & \\
508 & 0.2 & 508 & 0.39 & 508 & 0.41 & 508 & 0.44 & CCC bend \\
762 & 3 & 757 & 0.77 & 758 & 0.83 & 758 & 0.87 & Ring breathing \\
1379 & 1 & 1375 & 1 & 1376 & 1 & 1376 & 1 & CC str.; ring def. \\
1575 & 0.65 & 1575 & 0.12 & 1576 & 0.13 & 1576 & 0.15 & C=C str. \\
1627 & 0.05 & 1627 & 0.04 & 1628 & 0.05 & 1628 & 0.05 & C $=$ C str. \\
3050 & 0.82 & 3055 & 0.06 & 3055 & 0.12 & 3055 & 0.18 & CH str. \\
\hline
\end{tabular}

Some changes were also examined on $\mathrm{CD}$ vibrational modes after inclusion complex formation. For example, a change in the relative intensities of the doublet at $927-943 \mathrm{~cm}^{-1}$ was observed as well as for the bands located between 1050 and $1200 \mathrm{~cm}^{-1}$. To have a better insight on such changes, the figure 5 shows the subtractions of the isolated CD spectrum from normalized 2 $\beta C D: 1 N A P, 1 \beta C D: 1 N A P, 1 \beta C D: 2 N A P$ complexes spectra. The observation of several positive and negative peaks superimposed with the NAP modes indicates that a large number of the $\mathrm{CD}$ vibrational modes are strongly modified by the interaction with the NAP molecule. The most impacted vibrational modes are related with skeletal vibrations $\left(478 \mathrm{~cm}^{-1}\right.$, $850 \mathrm{~cm}^{-1}, 927 \mathrm{~cm}^{-1}$ ) (Egyed 1990), O-H wagging (562 $\mathrm{cm}^{-1}$ ) (Yao et al. 2014), C-O stretching $\left(943 \mathrm{~cm}^{-1}, 1051 \mathrm{~cm}^{-1}, 1076 \mathrm{~cm}^{-1}, 1124 \mathrm{~cm}^{-1}\right.$ ) (Yao et al. 2014) and C-H stretching or wagging $\left(1345 \mathrm{~cm}^{-1}, 2914 \mathrm{~cm}^{-1}, 2966 \mathrm{~cm}^{-1}\right.$ ) (Yao et al. 2014). We observed that the spectral 
modifications become more visible when the number of naphthalene molecules increase compared to $\mathrm{CD}$ ones, since the intensities of the negative or positive bands increase. Thus, the host/guest complex behaves as a global system that induces large variation on the vibrational modes of both compounds.

Fig.5 Normalized Raman spectra obtained after $\beta-C D$ spectrum subtraction from

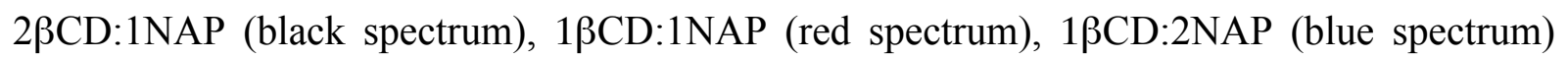
inclusion complexes spectra. The bottom Raman spectrum corresponds to the isolated NAP.

\section{Study of complexes between $\alpha, \beta, \gamma C D$ with TOL, NAP and FL}

Further investigations on CDs ability to form the complexes were realized by mixing selected aromatic compounds: TOL, NAP and FL dissolved in ethanol, with the saturated aqueous solutions of each $\mathrm{CD}(\alpha \mathrm{CD}, \beta C D$ and $\gamma \mathrm{CD})$. This study was performed to determine the ability of complex formation between the host and the guest in regards to their sizes.

\subsection{Thermogravimetric analysis}

In this part, a study of the inclusion compounds of the three types $\mathrm{CD}(\alpha \mathrm{CD}, \beta \mathrm{CD}$ and $\gamma \mathrm{CD})$ is presented using TOL, NAP and FL molecules as guests. Decomposition temperatures were found for each pollutant molecule: total mass loss of TOL was recorded from ambient till 113 ${ }^{\circ} \mathrm{C}$, NAP (as mentioned in the section 1.1) decomposes from 80 to $160{ }^{\circ} \mathrm{C}$ and FL thermal decomposition occurs from 125 to $280^{\circ} \mathrm{C}$. For the pure $\mathrm{CD}$, no important dissimilarity in the degradation temperature regarding to the cavity size was found.

Generally, an increasing number of guest molecules involved in the complex was expected (with an increasing cavity size $(\alpha \mathrm{CD}<\beta \mathrm{CD}<\gamma \mathrm{CD})$ ). The $\gamma \mathrm{CD}$ cavity is the wider and may be able to accommodate two guest molecules (Sardo et al. 2009). On the contrary, $\alpha \mathrm{CD}$ is the smaller host so its cavity is not large enough to accommodate one aromatic guest. Usually, one guest is stacked between two aCDs (Nolasco et al. 2009).

As shown in the first part, the inclusion of the guest into the cavity of the CD permits the guest to withstand higher temperature comparing to free molecules. For instance, toluene which is known to have a boiling point at $111^{\circ} \mathrm{C}$, was found to decompose at more than $270^{\circ} \mathrm{C}$ when it is in contact with the $\alpha \mathrm{CD}$. 
Table 3 shows the calculated stoichiometries for the host/guest complexes. As expected, in the case of TOL, complexes are composed of one guest molecule between two $\alpha \mathrm{CDs}$ (1:2 stoichiometry), whereas one molecules of TOL can be included in one molecule of both: $\beta C D$ and $\gamma \mathrm{CD}(1: 1)$. As a consequence, in the system of $2 \alpha \mathrm{CD}$ :1TOL a shift towards higher decomposition temperature was found, showing higher thermal stability.

Concerning NAP, one guest per one host molecule was calculated regardless to the cavity dimension. Unexpectedly, we observed that thermal stability of the NAP molecules is also independent on the size of the host. This behaviour could be related with different orientation of guest molecule inside the cavity of guest.

Finally, FL molecules formed a complex only with $\gamma \mathrm{CD}$. Indeed, in this case, calculation revealed that two $\gamma \mathrm{CD}$ molecules were engaged with one molecule of FL.

Table 3 TG analysis based calculation on stoichiometry for inclusion complexes

\begin{tabular}{|c|c|c|c|c|c|}
\hline System & $\begin{array}{c}{ }^{\circ} \mathrm{C} \\
\text { (Guest) }\end{array}$ & $\begin{array}{l}\%(w t) \\
\text { (Guest) }\end{array}$ & $\begin{array}{l}\%(w t) \\
\left(\mathrm{H}_{2} \mathrm{O}\right)\end{array}$ & $\begin{array}{c}\text { Calculated } \\
\text { stoichiometry }\end{array}$ & $\begin{array}{c}\text { Water per } \\
C D\end{array}$ \\
\hline$\alpha C D: T O L$ & 273 & 4 & 7.3 & $2: 1$ & 6 \\
\hline$\alpha C D$ : NAP & 268 & 9.9 & 7.5 & $1: 1$ & 6 \\
\hline$\beta C D$ : TOL & 268 & 3.5 & 8.8 & $1: 1$ & 9 \\
\hline$\beta C D$ : NAP & 269 & 5.1 & 7.2 & $1: 1$ & 7 \\
\hline$\gamma \mathrm{CD}: \mathrm{TOL}$ & 265 & 3.5 & 8.2 & $1: 1$ & 9 \\
\hline$\gamma \mathrm{CD}: \mathrm{NAP}$ & 270 & 2.7 & 7.4 & $1: 1$ & 9 \\
\hline$\gamma \mathrm{CD}: \mathrm{FL}$ & 272 & 5.1 & 8.2 & $2: 1$ & 9 \\
\hline
\end{tabular}

\subsection{Raman spectroscopy based analysis}

Raman spectroscopy measurements were performed on complexes in order to observe spectral evidence of guest-host interactions. It has already been observed that small shifts and variation in intensities for some bands in Raman spectra of the guest molecule appear upon formation of inclusion complexes (Amado et al. 1994; Amado and Ribeiro-Claro 2000). The moieties of guest molecules that suffer from intermolecular interactions can be identified by assigning the shifted bands using DFT calculation. Starting from the nature of vibrations modified upon complexation, it becomes also possible to discuss about the orientation of the guest molecules in the inclusion complexes. 
Quantum chemical computations predicting harmonic frequencies and spectral intensities are essential for interpretation of experimental spectra, particularly for large molecules. Accurate computation of IR and Raman intensities is difficult because of their dependence on dipole moment and polarizability derivatives. For this reason, it is invariably the relative, rather than absolute, band intensities that are used since experimental determination of absolute band intensities, especially for Raman bands, is difficult. Accordingly, the intensity of some bands is enhanced in experimental data in comparison with the calculated ones, especially for the more intensive bands, but the order of magnitude is kept on the whole spectra (Zvereva et al. 2010)

In experimental IR absorption spectra of inclusion complexes, bands due to CD are prominent (Nagao et al. 2009) while it is not so obvious in Raman spectra. Hence, it becomes easier to observe Raman bands attributed to the guest molecules.

The figure 6 shows the Raman spectra of complexes formation of CDs with TOL and NAP respectively. Both graphs $\mathrm{A}$ and $\mathrm{B}$ are composed of isolated pollutant spectrum (a) and the spectra of guests engaged in complexes with $\alpha \mathrm{CD}$ (c), $\beta C D(\mathrm{e})$ and $\gamma \mathrm{CD}(\mathrm{g})$. The native CDs spectra (b), (d) and (f) for $\alpha, \beta, \gamma C D$ respectively are also given.

As demonstrated previously by study based on TG analysis, TOL and NAP form complexes with all three kinds of CD. Some weak peaks attributed to TOL vibrations were observed in Raman spectra, confirming the TOL contribution in complexes formation. Unexpectedly, TOL vibrational modes are just weakly impacted by interaction with host molecule. Subtle changes can be noticed in the position of peaks assigned to in plane C-C stretch and ring deformation at $516 \mathrm{~cm}^{-1}$, methyl group stretch at $781 \mathrm{~cm}^{-1}$ and in plane $\mathrm{C}=\mathrm{C}$ stretching at $1026 \mathrm{~cm}^{-1}$ (vibrational modes assignment was found in literature (Tasumi et al. 1986)). Worth noting, that latter peak was absent in the spectrum of the $\alpha \mathrm{CD}$ :TOL complex. The more impacted vibrations related with $\mathrm{C}-\mathrm{H}$ stretching modes were observed. Unfortunately, analysis of C-H stretching mode belonging to methyl group at $2921 \mathrm{~cm}^{-1}$ is rather impossible due to strong signal of CDs in this region. However, other peak representing later mode in the ring presented at $3058 \mathrm{~cm}^{-1}$ was found to remarkably decrease after complex formation. The comparison of shift in positions of the peaks belonging to isolated TOL and TOL engaged to the complexes with CDs can be found in Online Resource table 6.

The interactions with TOL have caused more steric hindrance on $\alpha \mathrm{CD}$ molecules than on the ones having larger diameter of cavity. Comparable effect on $\alpha \mathrm{CD}$ vibrations was observed in 
the case of interaction with NAP. In contrary, just small disturbance on $\gamma \mathrm{CD}$ vibrations can be noticed after hosting these two aromatic guests.

Fig.6 Raman spectra of complexes formed based on CDs with TOL and NAP are presented in graph $\mathrm{A}$ and $\mathrm{B}$ respectively. In each graphs a), b), d), f) spectra are indicating vibrations of isolated pollutant, $\alpha \mathrm{CD}, \beta C D$ and $\gamma \mathrm{CD}$ respectively; Raman spectra of the inclusion complexes between pollutants and $\alpha \mathrm{CD}, \beta C D$ and $\gamma \mathrm{CD}$ are given in $\mathrm{b}$ ), d) and f) respectively.

The analysis of NAP peaks in inclusion complexes spectra revealed similarities with those discussed previously (1.1 section). The most impacted modes by the complexation are related with the ring breathing, ring deformation, $\mathrm{C}-\mathrm{C}$ central stretching and $\mathrm{C}-\mathrm{H}$ in plane stretching located at $761 \mathrm{~cm}^{-1}, 1379 \mathrm{~cm}^{-1}, 3050 \mathrm{~cm}^{-1}$ respectively (figure 4). Furthermore, considering relative intensities of these peaks, some differences were observed regarding the diameter of host cavity. The $\mathrm{C}-\mathrm{H}$ symmetric stretch is supposed to be more constrained if NAP is inserted in horizontal or diagonal orientations into the CDs cavity. These orientations can be achieved in $1 \beta C D: 1 N A P$ and $1 \gamma C D: 1 N A P$ systems. Calculated relative intensities of the peak at 3050 $\mathrm{cm}^{-1}$ showed less intensity in latter systems confirming guest diagonal orientation. Contrary, in complex with $\alpha \mathrm{CD}$ decrease in $\mathrm{C}-\mathrm{H}$ stretching mode intensity is less important, suggesting the vertical guest orientation. Latter NAP orientation can be further confirmed analyzing peak at $1379 \mathrm{~cm}^{-1}$. This vibrational mode is less impacted when NAP is included vertically into the smallest CD. Worth noting, that a slight shift of this vibration was observed. However, for the complexes with $\beta C D$ and $\gamma C D$ it shifted to a lower frequency by $3 \mathrm{~cm}^{-1}$ and in the case of complex with $\alpha \mathrm{CD}$ it is moved by $2 \mathrm{~cm}^{-1}$ to a higher frequency, again indicating different guest interaction with the host molecule. Furthermore, comparing relative intensities of this peak was noticed that in NAP interaction with $\alpha \mathrm{CD}$ case it increases two times and in case of interaction with other two hosts this vibration is three times more intense. Collation of calculated NAP vibrational modes with the relative intensities as well as of the experimentally achieved isolated NAP and NAP engaged in complexes is presented in Online Resource table 7. To find relative intensities of NAP peaks, spectra of CDs with included NAP and the spectra of the isolated CDs were normalized regarding the peak at $2879 \mathrm{~cm}^{-1}$ (corresponding to the in plane C-H stretching vibration). Then the spectra of isolated CDs were subtracted from the complexes ones and compared with NAP spectrum regarding the peak at $1025 \mathrm{~cm}^{-1}$ (corresponding to symmetric in plane C-C stretching motion). 
In our case, shifts in frequency and intensity of the guest peaks are mostly observed for the complex between $\gamma \mathrm{CD}$ and FL demonstrating that intermolecular interactions involved in its formation are stronger than those involved in the association of TOL and NAP in the hosts. As mentioned before, FL is compatible just with $\gamma \mathrm{CD}$ diameter of cavity for inclusion complex formation. TG analysis study has revealed that FL embedded into CD has a stoichiometry of two FL molecules in complex with one molecule of host. FL structure includes the five member cycle connecting naphthalene and benzene units (figure 1b)) and most likely latter units would be responsible for an interaction with the $\gamma \mathrm{CD}$ cavities. Raman spectroscopy based analysis confirmed this arrangement, since these units have few isolated non-overlapping vibrational modes which can be studied independently. With the help of literature (Manal 2011), we have calculated the FL vibration frequencies and Raman scattering intensities of all the 72 normal modes. We present them in Online Resource table 8 together with the achieved experimental values of isolated FL and of its complex with $\gamma \mathrm{CD}$.

Fig.7 Raman spectra of FL calculated and experimentally obtained are presented in graph a) and $b)$ respectively. The spectrum c) corresponding to a free $\gamma \mathrm{CD}$ and spectrum $\mathrm{d}$ ) corresponds to the complex formed between FL and $\gamma \mathrm{CD}$.

Many important spectral changes of FL can be observed in regards to complexation. The spectral comparison can be seen in figure 7, where FL spectra (obtained by calculations a) and experimentally b)) are plotted together with spectrum of FL embedded between $\gamma$ CDs d). The spectrum c) is corresponding to the isolated $\gamma \mathrm{CD}$.

The most important vibrational modes impacted by a complexation are related with the two moieties $\mathrm{A}$ and $\mathrm{B}$ that must be both involved in intermolecular interactions (scheme of molecule is presented in figure $1 \mathrm{~b})$ ). For instance, intensities of in plane $\mathrm{C}-\mathrm{C}$ and $\mathrm{C}-\mathrm{H}$ bending seen in FL spectrum at $560 \mathrm{~cm}^{-1}$ for ring A breathing and at $669 \mathrm{~cm}^{-1}$ for ring $\mathrm{B}$, decrease significantly upon complexation. Other evidence is related with the three equivalent in plane $\mathrm{C}-\mathrm{H}$ rocking and $\mathrm{C}-\mathrm{C}$ stretching observed in $\mathrm{FL}$ spectrum at $1018 \mathrm{~cm}^{-1}$ for ring $\mathrm{B}$, $1409 \mathrm{~cm}^{-1}$ for both rings and $1608 \mathrm{~cm}^{-1}$ for ring A. All of them equally decreased and it can be explained by steric hindrances of FL molecule included into host. The important shifts in frequency, superior to $10 \mathrm{~cm}^{-1}$, are observed for $\mathrm{C}-\mathrm{H}$ asymmetric stretching upon 
complexation at 3037, 3051 and $3059 \mathrm{~cm}^{-1}$. Those three families of modified vibrations: two breathing vibrations, three $\mathrm{C}-\mathrm{H}$ rocking and $\mathrm{C}-\mathrm{C}$ stretching vibrations and asymmetrical $\mathrm{C}-\mathrm{H}$ stretching vibrations can be considered as fingerprint of complexation.

Summarized comparison of the discussed FL vibrational modes with their shifted positions and changed intensities upon complexation is presented in table 4. To find relative intensities of FL peaks, firstly, spectra of CD with included FL and $\gamma \mathrm{CD}$ were normalized regarding the peak at $2879 \mathrm{~cm}^{-1}$ (corresponding to the in plane C-H stretching vibration). Secondly, the spectrum of isolated $\gamma \mathrm{CD}$ was subtracted from the complex one and then compared with FL spectrum regarding the peak at $1101 \mathrm{~cm}^{-1}$ (corresponding to symmetric in plane C-C-H and C$\mathrm{C}-\mathrm{C}$ bending motions).

Table 4 Comparison of FL peaks shifts and relative intensities (free FL and engaged in complexes with $\gamma \mathrm{CD}$ ). Numbers correspond to assignment in Online Resource table 8

\begin{tabular}{|c|c|c|c|c|}
\hline \multicolumn{2}{|c|}{$F L$} & \multicolumn{2}{|c|}{ Complex } & \multirow[t]{2}{*}{ Assignment } \\
\hline Peak & Rel.Int. & Peak & Rel.Int & \\
\hline 560 & 1.40 & 559 & 0.62 & $\mathrm{~N}^{\circ} 14$ dring ( $\left.\delta \mathrm{CCC}\right)$ A breathing \\
\hline 669 & 2.73 & 669 & 0.65 & $\mathrm{~N}^{\circ} 19$ dring $(\delta C C C) \mathrm{B}$ breathing \\
\hline 1018 & 1.25 & 1016 & 0.35 & $\mathrm{~N}^{\circ} 37$ dring $\mathrm{B}$ ( $\mathrm{CH}$ rock. and $\mathrm{CC}$ str.) \\
\hline 1101 & 1.00 & 1102 & 1.00 & $\mathrm{~N}^{\circ} 40$ dring ( $\mathrm{CCH}$ and $\mathrm{CCC}$ bending) \\
\hline 1409 & 1.71 & 1410 & 0.67 & $\mathrm{~N}^{\circ} 52$ dring ( $\mathrm{CH}$ rock. and $\mathrm{CC}$ str.) \\
\hline 1608 & 1.72 & 1610 & 1.14 & $\mathrm{~N}^{\circ} 60$ dring $\mathrm{A}$ ( $\mathrm{CH}$ rock. and $\mathrm{CC}$ str.) \\
\hline 3022 & 0.17 & 3037 & 0.05 & $\mathrm{~N}^{\circ} 63-65 \delta \mathrm{CH}$ Asym. Str. \\
\hline 3034 & 0.09 & 3051 & 0.24 & Nº6 $\delta \mathrm{CH}$ Asym. Str.(ring B) \\
\hline 3048 & 0.83 & 3059 & 0.05 & N67-69 $\delta C H$ Str. \\
\hline
\end{tabular}

$\gamma$ out plane of the molecule

$\delta$ in plane of the molecule

Graphical illustration of vibrational modes which were found to be the most affected when FL is engaged in the complexes with $\gamma \mathrm{CD}$, is presented in figure 8 . 
Fig. 8 The main normal modes of FL vibrations mostly impacted by the complexation $(\mathrm{C}-\mathrm{H}$ asymmetrical stretching modes are not represented). Numbers correspond to assignment in tables 4 and Online Resource table 8.

Finally, the changes in $\gamma \mathrm{CD}$ vibrations have appeared due to FL inclusion. Mostly they are related with C-O stretching modes $\left(945 \mathrm{~cm}^{-1}, 1059 \mathrm{~cm}^{-1}, 1069 \mathrm{~cm}^{-1}\right)$ (Yao et al. 2014) and C-H stretching or wagging modes $\left(1341 \mathrm{~cm}^{-1}, 2875 \mathrm{~cm}^{-1}, 2934 \mathrm{~cm}^{-1}\right)$ (Yao et al. 2014).

\section{The CDs selectivity for complex formation. Test of specificity}

The CDs selectivity discussed in previous section was herein tested by mixing each CD with a solution of the three pollutants (TOL, NAP, FL). Experiments were performed by drop-wise addition of the ethanol solution containing three pollutants into saturated aqueous solutions of each CD. A different procedure was applied for $\alpha \mathrm{CD}$ : in this case FL was absent in mixture of pollutants. Figure 9 presents achieved spectra of complexes formed between guests and $\alpha \mathrm{CD}$ a), $\beta C D$ c) and $\gamma \mathrm{CD}$ e). They were normalized regarding the band at $2879 \mathrm{~cm}^{-1}$ corresponding to a $\mathrm{C}-\mathrm{H}$ stretching vibration of $\mathrm{CD}$ and compared to $\mathrm{CD}$ native forms: $b$ ), d), f) for $\alpha \mathrm{CD}$, $\beta C D, \gamma C D$ respectively as well as the pollutants spectra: $g$ ), h), i) for TOL, NAP and FL respectively.

To determine the selective interaction of the $\mathrm{CD}$ with specific pollutants, we have calculated the ratio between the Raman intensity of the pollutants involved in the CD complex for both experiments: individual pollutant and mixture of pollutants. This ratio has been calculated as follow:

Guest $\%=$ Iguest peaks ICD, $\quad \mathrm{C}-\mathrm{H}$ modeindividual*ICD, $\mathrm{C}-\mathrm{H}$ modeIguest peaksmixed $* 100 \%$

The first term corresponds to the relative intensity of the individual pollutant in the $\mathrm{CD}$ complex whereas the second term corresponds to the relative intensity of the pollutant in the $\mathrm{CD}$ complex in the case of the mixture. Both relative intensities were normalised by the intensity of the $\mathrm{C}-\mathrm{H}$ vibration mode of the $\mathrm{CD}$ in order to use the $\mathrm{CD}$ as a reference. This ratio 
is then independent on the Raman cross section of the pollutant modes and allows comparing directly the proportion of pollutants forming a complex with the CD.

Raman spectra of precipitants collected after mixing $\alpha \mathrm{CD}$ with TOL and NAP shows the appearance of peaks belonging to both pollutants (roman numerals I and II indicated peaks from TOL and NAP respectively). Further calculation of the relative intensities belonging to TOL peak located at $1029 \mathrm{~cm}^{-1}$ and NAP peak at $761 \mathrm{~cm}^{-1}$ revealed that $62 \pm 7 \%$ of complexes in this system are formed between TOL and $\alpha \mathrm{CD}$. This latter result demonstrates higher affinity of the $\alpha \mathrm{CD}$ to the TOL then to the NAP. On the contrary, $92 \pm 5 \%$ of NAP was found in the complex formed between $\beta C D$ and mixture of pollutants. Calculation of relative intensities of the peaks belonging to NAP and further comparison with the values presented in table 1 confirmed 1 $\beta C D$ :1NAP stoichiometry in the system. Raman spectrum of precipitants collected after mixing $\gamma \mathrm{CD}$ with three pollutants, showed peaks coming from NAP and FL (roman numerals II and III indicated peaks from NAP and FL respectively). Calculation of relative intensities of guests vibrational modes (peaks at $761 \mathrm{~cm}^{-1}$ for NAP and at $669 \mathrm{~cm}^{-1}$ for FL) revealed that FL dominates in this system forming $70 \pm 9 \%$ of all complexes with $\gamma \mathrm{CD}$. The explanation of why no inclusion of TOL in $\beta \mathrm{CD}$ and $\gamma \mathrm{CD}$ occurred can be related with the competitive exchange in parallel reactions. Another reason contributing more in $\gamma \mathrm{CD}$ case is that the size of the cavity is not adapted to a small TOL molecule. As a consequence, a molecule smaller than the cavity will have less interactions (hydrophobic, van der Waals, etc) and thus less affinity with the CD. Since TOL is the smallest molecule in this reaction and $\gamma \mathrm{CD}$ shows better affinity to bigger molecules, it is possible that interaction between TOL and the large cavity of CD is too low and can be easily replaced.

Fig.9 Raman spectra of complexes formed mixing aromatic molecules and $\alpha \mathrm{CD}, \beta C D, \gamma \mathrm{CD}$ are presented in graph a), c) and e) respectively. The spectra b), d), f) correspond to $\alpha \mathrm{CD}$, $\beta C D, \gamma C D$ respectively and $\mathrm{g}$ ), h), i) correspond to TOL, NAP and FL respectively.

\section{Conclusion}

In this study, results of TG analysis, Raman spectroscopy and DFT calculations provide information on the complexes formation between organic pollutants (TOL, NAP and FL) and three forms of $\mathrm{CDs}(\alpha, \beta, \gamma \mathrm{CD})$ in the solid state. In the first part of this study, three 
stoichiometries of $\beta C D$ :NAP system have been analyzed. The obtained results permit to rationalize the host-guest complex formation in regards to different stoichiometry. Second part of the study was dedicated to description of complexes formed between all selected pollutants with three kind of CD. Data collected from TG analysis suggested that mainly stoichiometry of one guest per one host was formed with the exception in $\alpha \mathrm{CD}$ :TOL and $\gamma \mathrm{CD}$ :FL systems, where one guest is interacting with two host molecules. It is noteworthy, that FL was found to form complex just with $\gamma \mathrm{CD}$ due to its larger size.

Using Raman spectroscopy, the most impacted vibrational modes after complexes formation, were analysed. In the case of TOL a strong decrease in relative intensity of ring $\mathrm{C}-\mathrm{H}$ stretching mode was observed. Other subtle changes were found for the motions related to the ring deformation, $\mathrm{C}=\mathrm{C}$ stretching and methyl group symmetric deformation. The study of NAP peaks assigned to the ring breathing, ring deformation, C-C central stretching and C-H in plane stretching gave the possibility to discuss of potential guest orientation inside the host cavity. Due to differences in the relative intensities of these modes we assumed that vertically orientated NAP is inserted into $\alpha \mathrm{CD}$ cavity. With the bigger hosts NAP is most likely interacting in diagonal or horizontal orientations. The spectroscopic evidences of a guest molecule orientation and intermolecular interaction were found especially obvious in the FL case. Three classes of mostly impacted vibrations were found and proposed as the fingerprint for a FL engaged in complex.

Finally, all achieved spectral evidences opened the way for analysis of more complexed systems. Test of CDs specificity regarding the guest size showed considerable affinity in the systems of $\alpha \mathrm{CD}$ :TOL, $\beta C D$ :NAP and $\gamma \mathrm{CD}$ :FL.

All achieved information could be exploited in the CDs applications related to the environmental pollution monitoring and remediation.

\section{Acknowledgements}

The authors would like to acknowledge the Remantas project (ANR-11-ECOT-0010), supported by French National Research Agency (ANR) for a financial support.

\section{Conflict of interest}

The authors declare no conflict of interest. 


\section{References}

Amado AM, Moreira da Silva AM, Ribeiro-Claro PJA, Teixeira-Dias JJC (1994) Metasubstituted styrene molecules included in cydodextrins: A Raman spectroscopic study Journal of Raman Spectroscopy 25:599-605 doi:10.1002/jrs.1250250721

Amado AM, Ribeiro-Claro PJA (2000) Selection of substituted benzaldehyde conformers by the cyclodextrin inclusion process: a Raman spectroscopic study J Raman Spectrosc 31:971-978 doi:10.1002/1097-4555(200011)31:11<971::aid-jrs627>3.0.co;2-r

Astray G, Gonzalez-Barreiro C, Mejuto JC, Rial-Otero R, Simal-Gándara J (2009) A review on the use of cyclodextrins in foods Food Hydrocolloids 23:1631-1640 doi:http://dx.doi.org/10.1016/j.foodhyd.2009.01.001

Bantz KC, Haynes CL (2009) Surface-enhanced Raman scattering detection and discrimination of polychlorinated biphenyls Vibrational Spectroscopy 50:29-35 doi:http://dx.doi.org/10.1016/j.vibspec.2008.07.006

Becke AD (1996) Density-functional thermochemistry. IV. A new dynamical correlation functional and implications for exact-exchange mixing The Journal of Chemical Physics 104:1040-1046 doi:doi:http://dx.doi.org/10.1063/1.470829

Buschmann HJ, Schollmeyer E (2002) Applications of cyclodextrins in cosmetic products: A review Journal of cosmetic science 53:185-191

Carron K, Peitersen L, Lewis M (1992) Octadecylthiol-modified surface-enhanced Raman spectroscopy substrates: a new method for the detection of aromatic compounds Environ Sci Technol 26:1950-1954 doi:10.1021/es00034a011

Chang LM, Ding Y, Li X (2013) Surface molecular imprinting onto silver microspheres for surface enhanced Raman scattering applications Biosens Bioelectron 50:106-110 doi:10.1016/j.bios.2013.06.002

Cireli A, Yurdakul B (2006) Application of cyclodextrin to the textile dyeing and washing processes J Appl Polym Sci 100:208-218 doi:10.1002/app.22863

Costa JCS, Sant'Ana AC, Corio P, Temperini MLA (2006) Chemical analysis of polycyclic aromatic hydrocarbons by surface-enhanced Raman spectroscopy Talanta 70:10111016 doi:http://dx.doi.org/10.1016/j.talanta.2006.01.036

Del Valle EMM (2004) Cyclodextrins and their uses: a review Process Biochem 39:10331046 doi:http://dx.doi.org/10.1016/S0032-9592(03)00258-9

Dennington R, Keith T, Millam J (2009) GaussView, Version 5. Semichem Inc., Shawnee Mission KS

Diggs DL et al. (2011) Polycyclic Aromatic Hydrocarbons and Digestive Tract Cancers: A Perspective Journal of Environmental Science and Health, Part C 29:324-357 doi:10.1080/10590501.2011.629974

Dufosse L, Souchon II, Feron G, Latrasse A, Spinnler HE (1999) In situ detoxification of the fermentation medium during gamma-decalactone production with the yeast sporidiobolus salmonicolor Biotechnol Prog 15:135-139 doi:10.1021/bp980113a

Egyed O (1990) SPECTROSCOPIC STUDIES ON BETA-CYCLODEXTRIN Vib Spectrosc 1:225-227 doi:10.1016/0924-2031(90)80041-2

Frisch MJ et al. (2009) Gaussian 09, Revision A.02. Gaussian, Inc., Wallingford, CT, USA 
García-Zubiri Í, González-Gaitano G, Sánchez M, Isasi J, Ramón (2004) Infrared Study of Solid Dispersions of $\beta$-Cyclodextrin with Naphthalene Derivitaves Journal of Inclusion Phenomena 49:291-302 doi:10.1023/B:JIPH.0000048317.30909.c5

Giordano F, Novak C, Moyano JR (2001) Thermal analysis of cyclodextrins and their inclusion compounds Thermochim Acta 380:123-151 doi:http://dx.doi.org/10.1016/S0040-6031(01)00665-7

Guerrini L, Garcia-Ramos JV, Domingo C, Sanchez-Cortes S (2006) Functionalization of Ag Nanoparticles with Dithiocarbamate Calix[4]arene As an Effective Supramolecular Host for the Surface-Enhanced Raman Scattering Detection of Polycyclic Aromatic Hydrocarbons Langmuir 22:10924-10926 doi:10.1021/1a062266a

Guerrini L, Garcia-Ramos JV, Domingo C, Sanchez-Cortes S (2009) Sensing Polycyclic Aromatic Hydrocarbons with Dithiocarbamate-Functionalized Ag Nanoparticles by Surface-Enhanced Raman Scattering Analytical Chemistry 81:953-960 doi:10.1021/ac801709e

Halvorson RA, Vikesland PJ (2010) Surface-Enhanced Raman Spectroscopy (SERS) for Environmental Analyses Environ Sci Technol 44:7749-7755 doi:10.1021/es101228z

Harris KL, Myers JN, Ramesh A (2013) Benzo(a)pyrene modulates fluoranthene-induced cellular responses in HT-29 colon cells in a dual exposure system Environ Toxicol Pharmacol 36:358-367 doi:http://dx.doi.org/10.1016/j.etap.2013.04.017

Hill W, Fallourd V, Klockow D (1999) Investigation of the adsorption of gaseous aromatic compounds at surfaces coated with heptakis(6-thio-6-deoxy)-beta-cyclodextrin by surface-enhanced Raman scattering J Phys Chem B 103:4707-4713 doi:10.1021/jp990574u

Koban W, Koch JD, Hanson RK, Schulz C (2004) Absorption and fluorescence of toluene vapor at elevated temperatures PCCP 6:2940-2945 doi:10.1039/b400997e

Köhler JEH, Grczelschak-Mick N (2013) The $\beta$-cyclodextrin/benzene complex and its hydrogen bonds - a theoretical study using molecular dynamics, quantum mechanics and COSMO-RS Beilstein Journal of Organic Chemistry 9:118-134 doi:10.3762/bjoc.9.15

Kvenvolden KA, Cooper CK (2003) Natural seepage of crude oil into the marine environment Geo-Mar Lett 23:140-146 doi:10.1007/s00367-003-0135-0

Lee C, Yang W, Parr RG (1988) Development of the Colle-Salvetti correlation-energy formula into a functional of the electron density Physical Review B 37:785-789

Lienig D (1980) J. M. Neff: Polycyclic Aromatic Hydrocarbons in the Aquatic Environment. 30 fig., 89 tab., 262 pp. - London: Applied Science Publishers 1979. Internationale Revue der gesamten Hydrobiologie und Hydrographie 65:898-898 doi:10.1002/iroh.19800650624

Liu Y, Chen G-S, Zhang H-Y, Song H-B, Ding F (2004) Interaction between $\beta$-cyclodextrin and 1,10-phenanthroline: uncommon 2:3 inclusion complex in the solid state Carbohydr Res 339:1649-1654 doi:http://dx.doi.org/10.1016/j.carres.2004.04.004

Loftsson T, Brewster ME (1996) Pharmaceutical applications of cyclodextrins. 1. Drug solubilization and stabilization J Pharm Sci 85:1017-1025 doi:10.1021/js950534b 
Maeda H, Maeda T, Mizuno K (2012) Absorption and fluorescence spectroscopic properties of 1- and 1,4-silyl-substituted naphthalene derivatives Molecules (Basel, Switzerland) 17:5108-5125 doi:10.3390/molecules 17055108

Manal OH (2011) Theoretical Study of Vibration Spectroscopy for Neutral and Charged Fluoranthene Molecule Journal of Baghdad for Science 8:366-374

Nagao A, Kan-no A, Takayanagi M (2009) Infrared spectra of monosubstituted toluene derivatives in cyclodextrin: Orientation of guest molecules in included complexes $\mathrm{J}$ Mol Struct 929:43-47 doi:http://dx.doi.org/10.1016/j.molstruc.2009.04.002

Nolasco MM, Amado AM, Ribeiro-Claro PJA (2009) Spectroscopic and thermal studies on the inclusion of trans-cinnamic acid and a number of its hydroxyl-derivatives with $\alpha, \beta$ and $\gamma$-cyclodextrins molecules J Raman Spectrosc 40:687-695 doi:10.1002/jrs.2182

O'Boyle NM, Tenderholt AL, Langner KM (2008) cclib: A library for package-independent computational chemistry algorithms J Comput Chem 29:839-845 doi:10.1002/jcc.20823

Pejcic B, Eadington P, Ross A (2007) Environmental Monitoring of Hydrocarbons: A Chemical Sensor Perspective Environ Sci Technol 41:6333-6342 doi:10.1021/es0704535

Pfannkuche J, Lubecki L, Schmidt H, Kowalewska G, Kronfeldt HD (2012) The use of surface-enhanced Raman scattering (SERS) for detection of PAHs in the Gulf of Gdansk (Baltic Sea) Mar Pollut Bull 64:614-626 doi:10.1016/j.marpolbul.2011.12.008

Readman JW, Fowler SW, Villeneuve JP, Cattini C, Oregioni B, Mee LD (1992) Oil and combustion-product contamination of the Gulf marine environment following the war Nature 358:662-665

Russell N, McNamara M (1989) FT-IR and raman spectral evidence for metal complex formation with $\beta$-cyclodextrin as a first sphere ligand J Inclusion Phenom Mol Recognit Chem 7:455-460 doi:10.1007/bf01079781

Saranya G, Kolandaivel P, Senthilkumar K (2011) Optical Absorption and Emission Properties of Fluoranthene, Benzo[k]fluoranthene, and Their Derivatives. A DFT Study The Journal of Physical Chemistry A 115:14647-14656 doi:10.1021/jp208617s

Sardo M, Amado AM, Ribeiro-Claro PJA (2009) Inclusion compounds of phenol derivatives with cyclodextrins: a combined spectroscopic and thermal analysis J Raman Spectrosc 40:1624-1633 doi:10.1002/jrs.2310

Shi X, Kwon Y-H, Ma J, Zheng R, Wang C, Kronfeldt HD (2012) Trace analysis of polycyclic aromatic hydrocarbons using calixarene layered gold colloid film as substrates for surface-enhanced Raman scattering J Raman Spectrosc:n/a-n/a doi:10.1002/jrs.4155

Singh R, Bharti N, Madan J, Hiremath S (2010) Characterization of cyclodextrin inclusion complexes - a review J Pharm Sci Technol 2:171-183

Srivastava A, Singh VB (2007) Theoretical and experimental studies of vibrational spectra of naphthalene and its cation Indian J Biochem Biophys 45:714-720

Tasumi M, Urano T, Nakata M (1986) Some thoughts on the vibrational modes of toluene as a typical monosubstituted benzene J Mol Struct 146:383-396 doi:http://dx.doi.org/10.1016/0022-2860(86)80306-4 
Trotta F, Zanetti M, Camino G (2000) Thermal degradation of cyclodextrins Polym Degrad Stab 69:373-379 doi:http://dx.doi.org/10.1016/S0141-3910(00)00084-7

Varanasi U, Stein JE, Nishimoto M, Reichert WL, Collier TK (1987) Chemical carcinogenesis in feral fish: uptake, activation, and detoxication of organic xenobiotics Environ Health Perspect 71:155-170

Viglianti C, Hanna K, de Brauer C, Germain P (2006) Removal of polycyclic aromatic hydrocarbons from aged-contaminated soil using cyclodextrins: Experimental study Environ Pollut 140:427-435 doi:http://dx.doi.org/10.1016/j.envpol.2005.08.002

Xie $\mathrm{Y}$ et al. (2011) Selective SERS detection of each polycyclic aromatic hydrocarbon (PAH) in a mixture of five kinds of PAHs J Raman Spectrosc 42:945-950 doi: $10.1002 / \mathrm{jrs} .2818$

Xie Y et al. (2010) Sensing of polycyclic aromatic hydrocarbons with cyclodextrin inclusion complexes on silver nanoparticles by surface-enhanced Raman scattering Analyst 135:1389-1394

Yang L, Ma L, Chen G, Liu J, Tian Z-Q (2010) Ultrasensitive SERS Detection of TNT by Imprinting Molecular Recognition Using a New Type of Stable Substrate Chem-Eur J 16:12683-12693 doi:10.1002/chem.201001053

Yao Q, You B, Zhou SL, Chen M, Wang YJ, Li W (2014) Inclusion complexes of cypermethrin and permethrin with monochlorotriazinyl-beta-cyclodextrin: A combined spectroscopy, TG/DSC and DFT study Spectrochim Acta, Part A 117:576586 doi:10.1016/j.saa.2013.09.036

Zvereva EE, Shagidullin AR, Katsyuba SA (2010) Ab Initio and DFT Predictions of Infrared Intensities and Raman Activities The Journal of Physical Chemistry A 115:63-69 doi:10.1021/jp108057p 
Figure 1
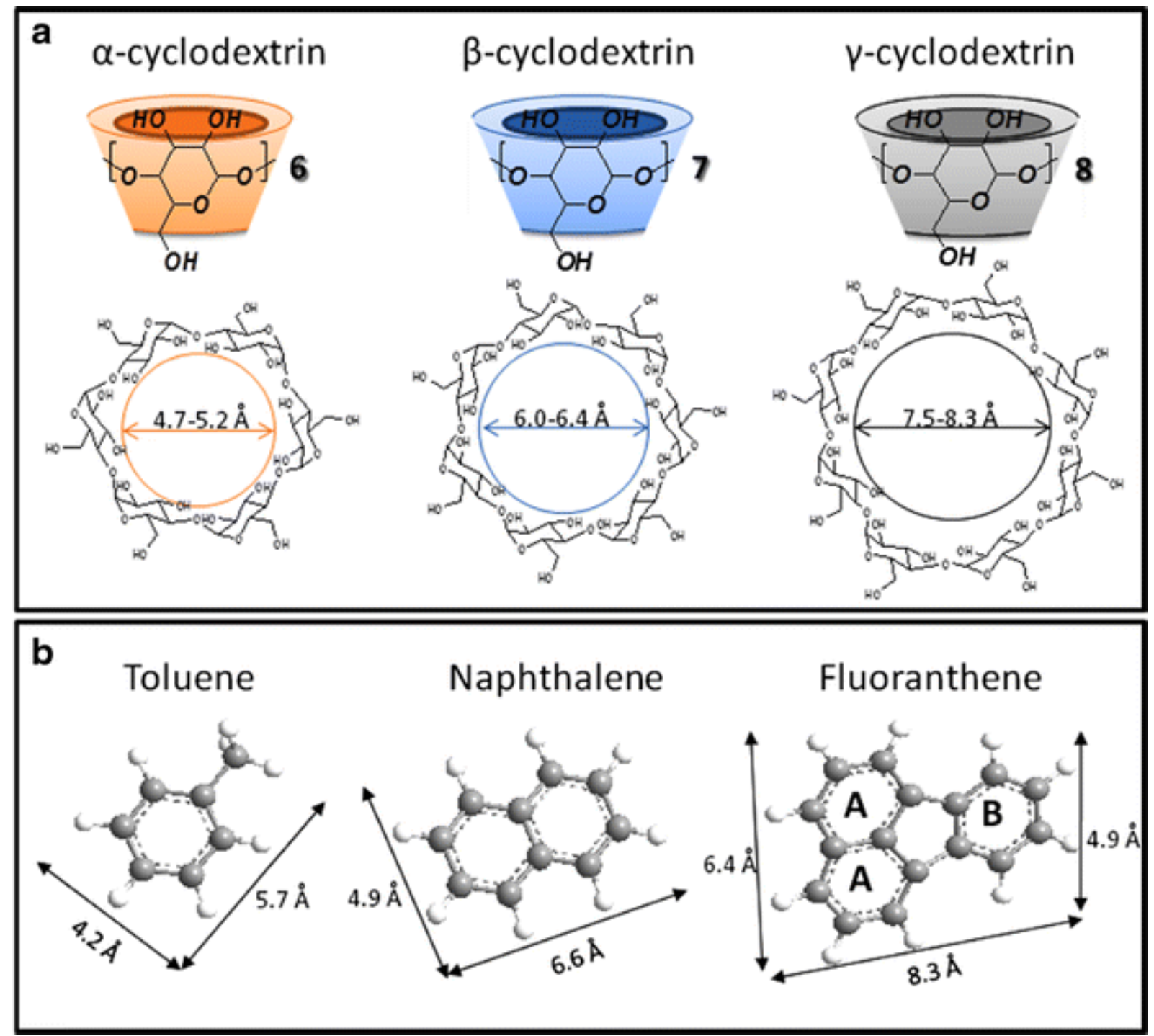
Figure 2

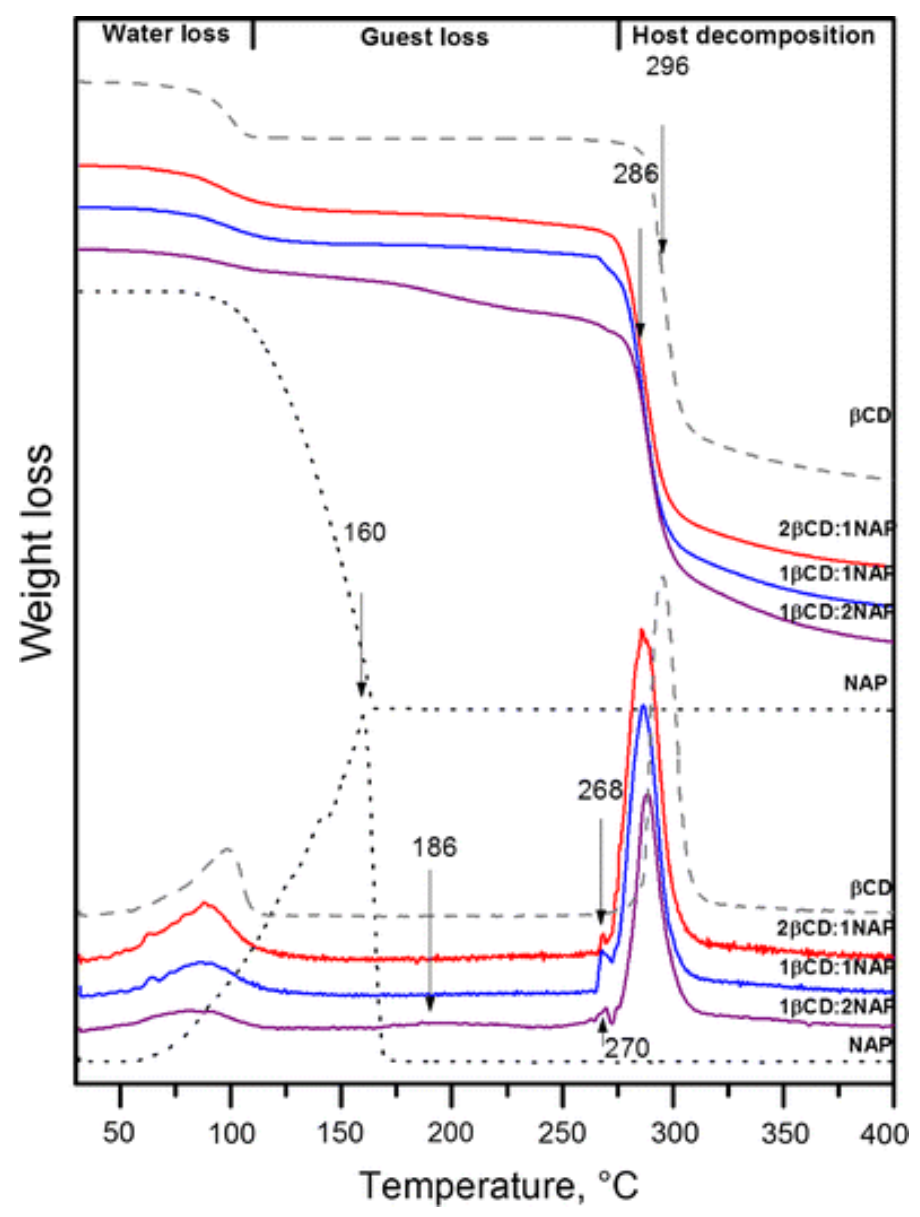

Figure 3

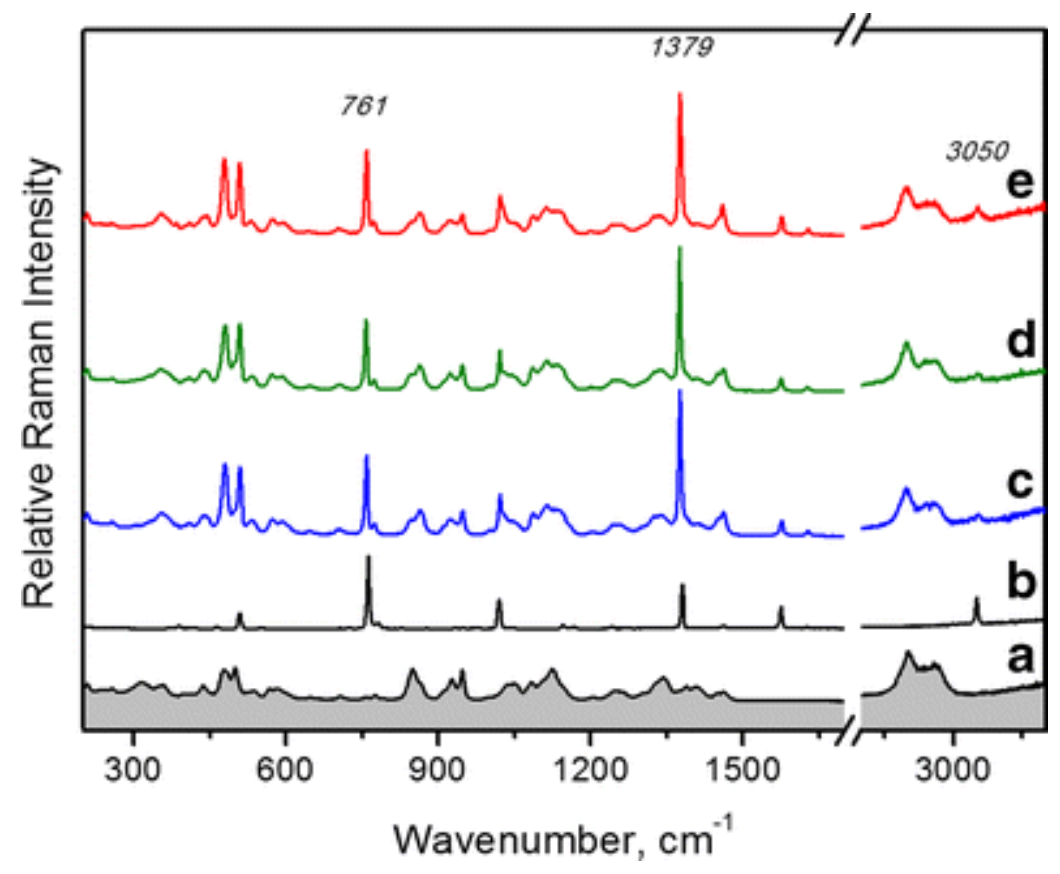


Figure 4

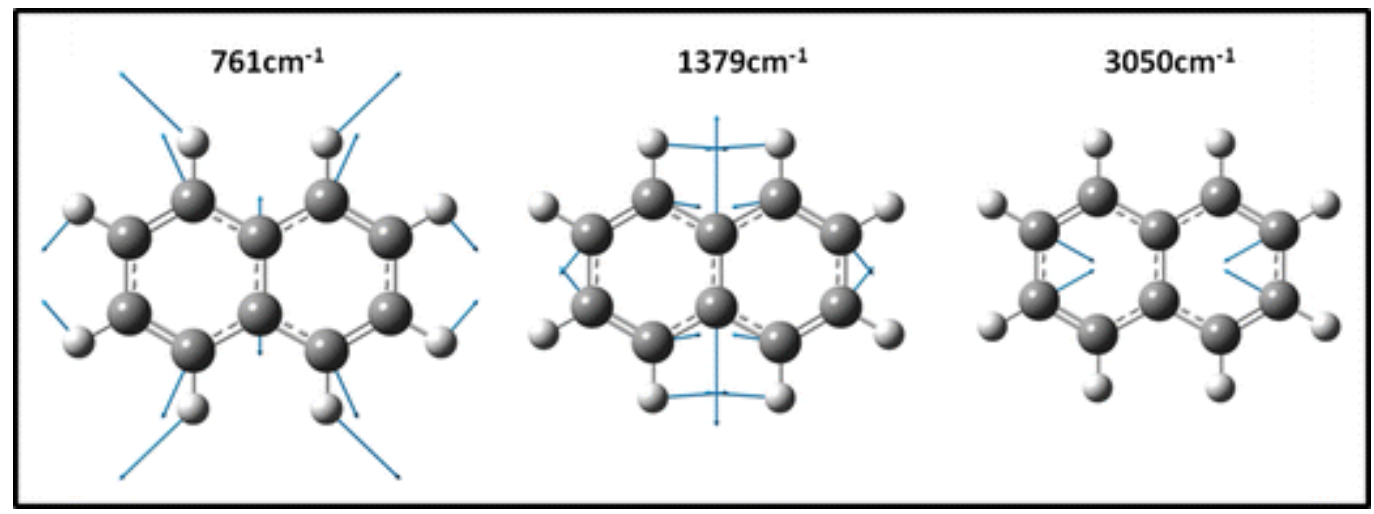

Figure 5

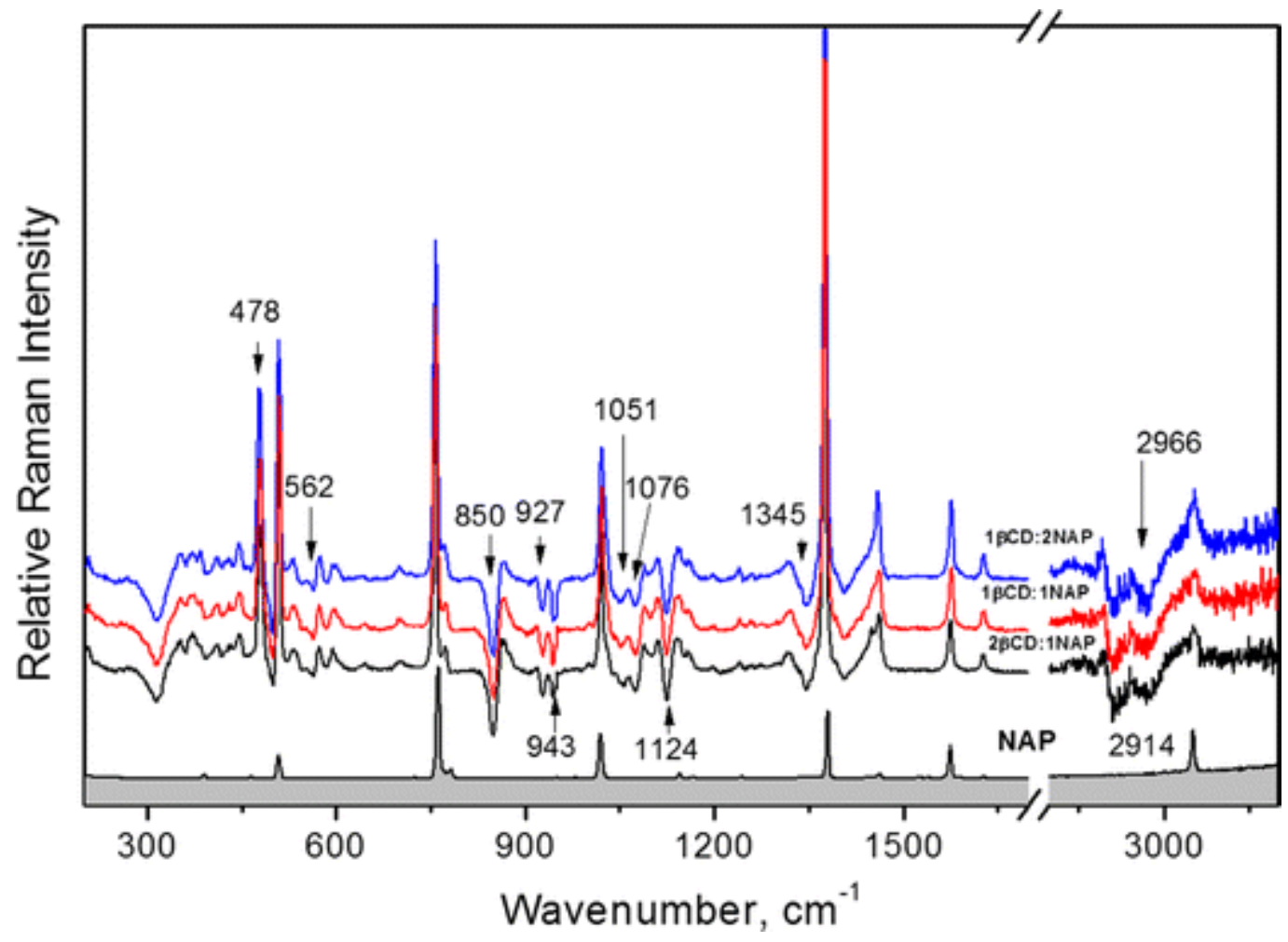


Figure 6

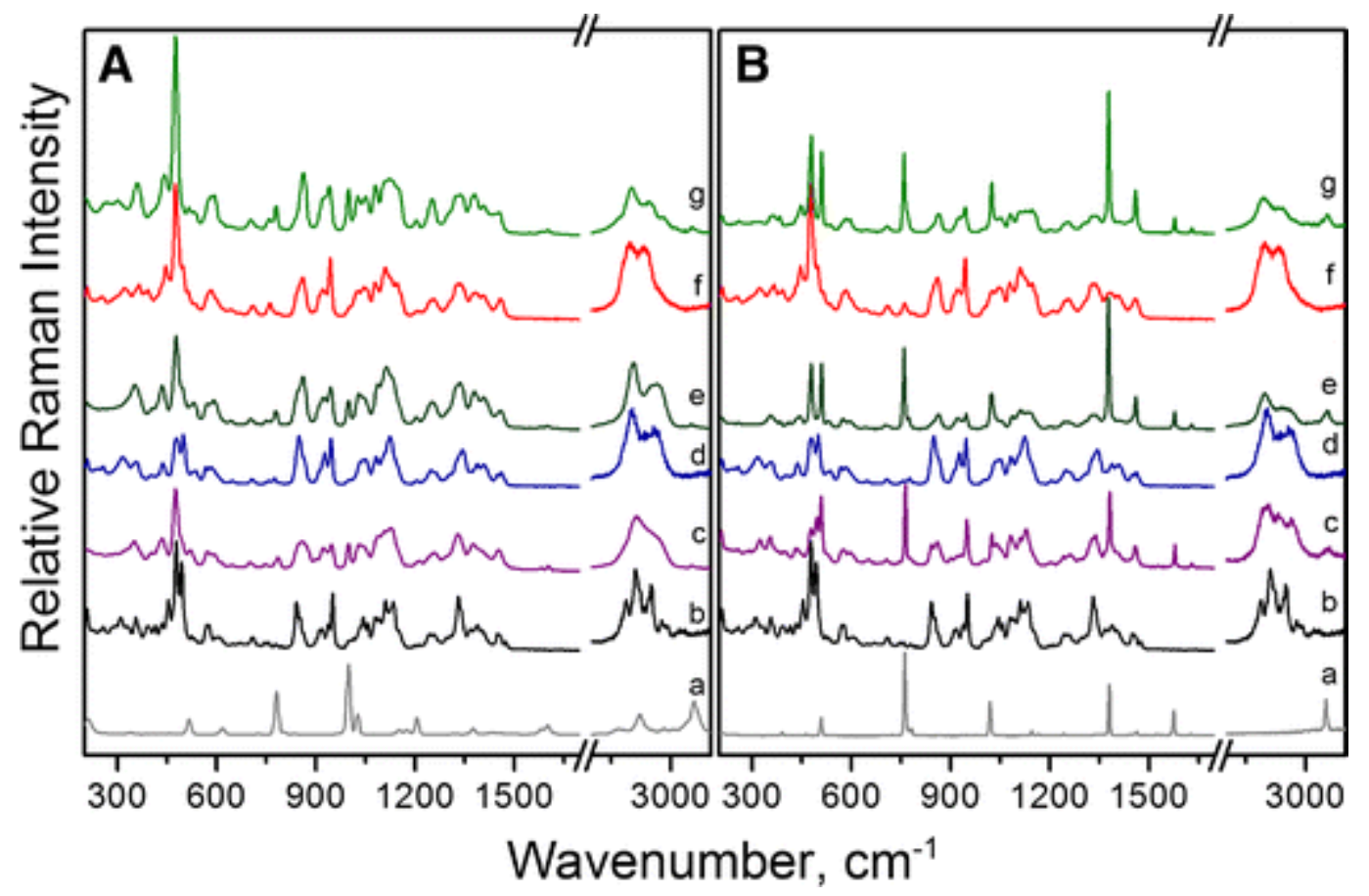

Figure 7

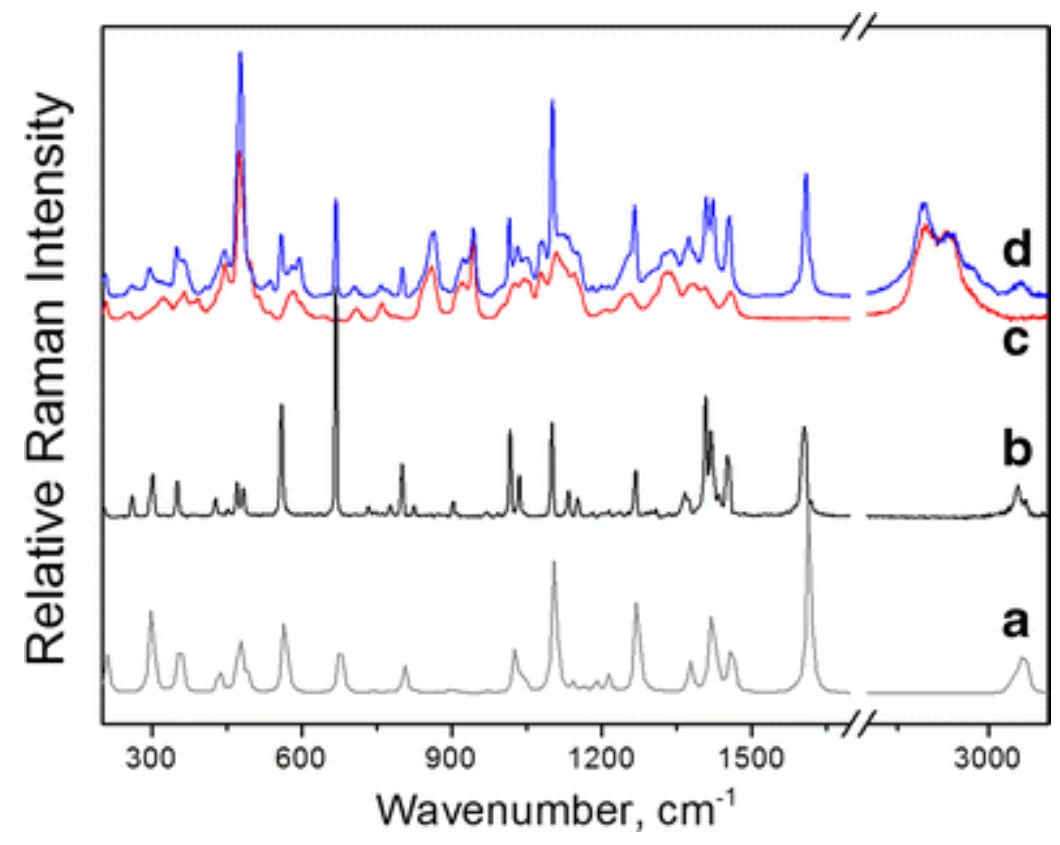


Figure 8

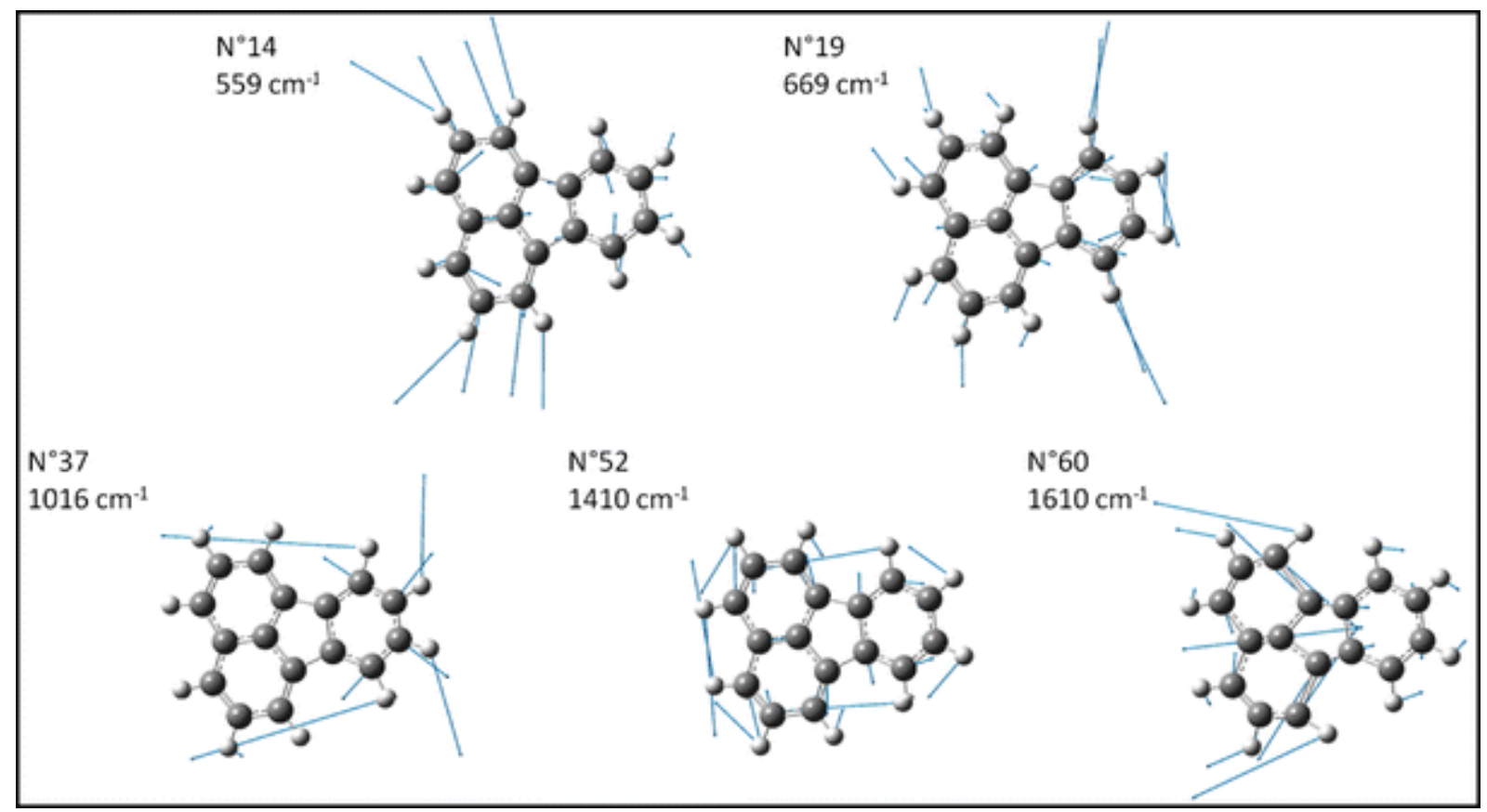

Figure 9

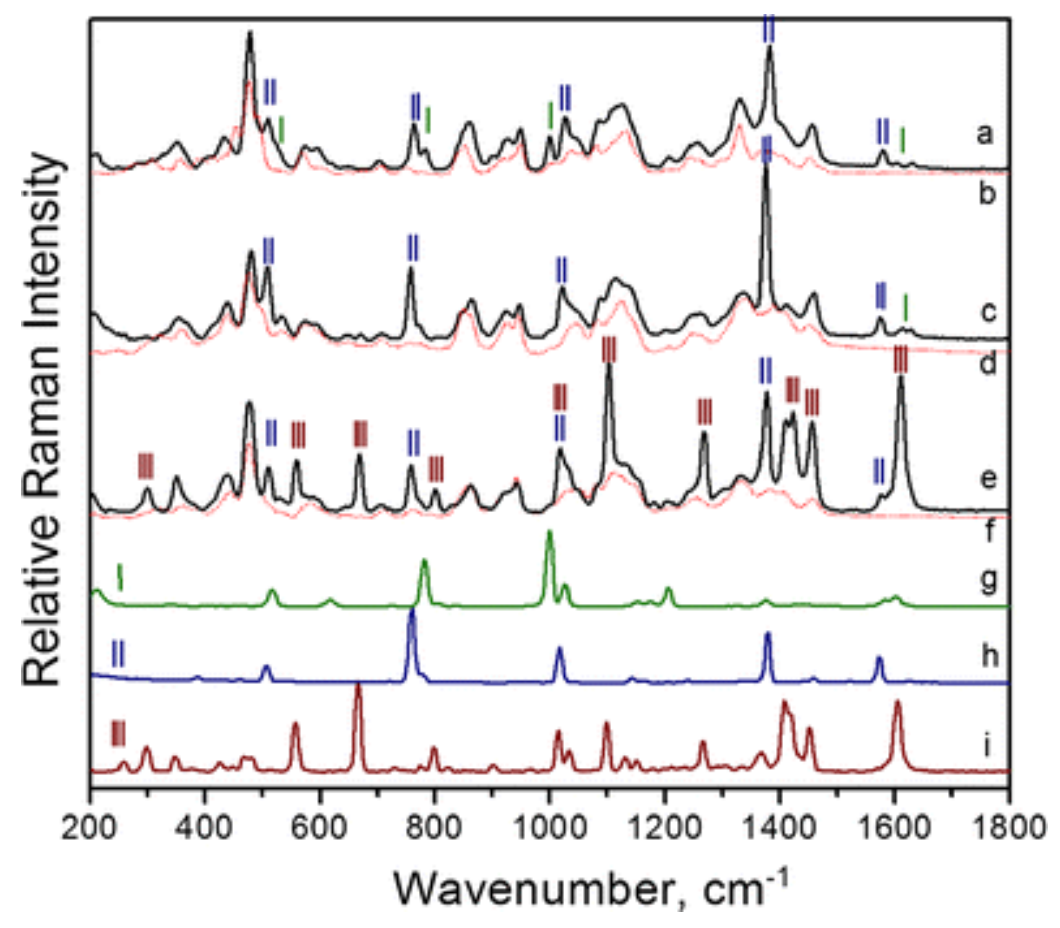

